\title{
A Agenda de Segurança Internacional no BRICS (2009-2019)
}

\author{
Leonardo Ramos ${ }^{1}$ \\ 1Professor do Departamento de Relações Internacionais da Pontifícia Universidade Católica de Minas \\ (PUC-MG). Belo Horizonte, MG. Brasil. \\ E-mail: lcsramos@pucminas.br \\ Pedro D. Rocha ${ }^{2}$ \\ ${ }^{2}$ Doutorando no Programa de Pós-graduação em Relações Internacionais Santiago Dantas \\ (UNESP-UNICAMP-PUC/SP). São Paulo, SP. Brasil. \\ E-mail:pd.rocha@unesp.br \\ Danny Zahreddine ${ }^{3}$ \\ 3Professor do Departamento de Relações Internacionais da Pontifícia Universidade Católica de Minas \\ (PUC-MG). Belo Horizonte, MG. Brasil. \\ E-mail: danny@pucminas.br

\section{INTRODUÇÃO}

Criado a partir de acrônimo originado no mercado financeiro para conter em especial os efeitos perversos da crise de 2008, hoje o BRICS assume características que sobrepujam sua própria origem. A expansão do grupo se dá ao mesmo tempo em termos institucionais, pela criação de organismos como o Arranjo Contingente de Reservas (ACR) e o Novo Banco de Desenvolvimento (NBD), e temáticos, pela inclusão paulatina de novos eixos de debate. Se antes predominavam discussões relativas à economia política internacional, especialmente aquelas ligadas ao desenvolvimento, questões de segurança internacional também passaram a ter importância significativa dentro do BRICS (Medeiros, Ribeiro e de Lyra, 2017; Van der Pijl, 2017).

Como marco desse processo destacam-se as cúpulas de Sanya (2011) e Delhi (2012). Em Sanya, pela primeira vez foi mencionada a necessidade de promover coordenação política entre os países do grupo em matéria de segurança; o que de fato foi impulsionado pela presença, naquele ano, de todos os cinco membros no Conselho de Segurança 
das Nações Unidas (CSNU). Com efeito, a cúpula de Delhi teve como tema central a questão Parceria do BRICS para a Estabilidade Global, Segurança e Prosperidade. Neste marco, argumenta-se que a intensificação da cooperação em segurança não configura por si só um desvio ao caráter tradicional do grupo, mas que deve ser compreendida a partir de dois processos articulados. Primeiro, o nexo desenvolvimento-segurança internacional. Na perspectiva dos principais atores constituintes do bloco, em muitos momentos os dois eixos não são contrários e excludentes, mas complementares: se a preservação da segurança é compreendida como fundamental para o desenvolvimento econômico, o próprio desenvolvimento econômico é por sua vez percebido como garantidor da segurança internacional. E segundo, os interesses particulares dos países membros do bloco em questões de segurança.

Assim, o objetivo geral deste artigo é analisar as discussões sobre segurança internacional dentro das cúpulas do BRICS, entre 2009 e 2019, observando quais foram seus principais eixos de discussão e como tal temática se insere na trajetória do próprio grupo. De modo a cumpri-lo, foi realizada uma análise de conteúdo das declarações de cúpula do grupo no período correspondente. Na análise destacaram-se seis categorias temáticas: i) terrorismo; ii) segurança cibernética; iii) tráfico de drogas e crime organizado transnacional; iv) corrupção e lavagem de dinheiro; v) paz e resolução de conflitos; e vi) desarmamento e não proliferação de armas de destruição em massa. Dentro de cada uma delas se sublinha a evolução das discussões e a abordagem do grupo às problemáticas. $\mathrm{O}$ artigo busca contribuir para a literatura em Relações Internacionais ao assinalar a maneira pela qual o nexo desenvolvimento-segurança, em geral, e a governança em segurança internacional, em particular, vem sendo pensados e postos em prática por potências emergentes. Busca também entender como, nesse processo, discussões sobre a relação entre segurança e desenvolvimento se articularam com interesses particulares dessas potências emergentes.

O texto segue em três seções. Na primeira, delineia de forma breve o que se entende pelo nexo desenvolvimento-segurança internacional e a sua incorporação paulatina dentro do BRICS. A segunda apresenta mais detalhadamente as metodologias e as técnicas de pesquisa que serviram de base para a análise de conteúdo das declarações de cúpula. Por fim, tendo como base esses apontamentos, a terceira seção expõe os eixos temáticos e a evolução das discussões do bloco, acerca da governança, no âmbito da segurança internacional. 


\section{O NEXO DESENVOLVIMENTO-SEGURANÇA INTERNACIONAL}

Nas últimas décadas, discussões nos âmbitos acadêmico e prático têm sido travadas no sentido de conectar as áreas de Desenvolvimento e Segurança Internacional. Tradicionalmente afastadas, passaram explicitamente a serem vistas como articuladas e complementares (Chandler, 2007). Durante a Guerra Fria, por exemplo, iniciativas como o Plano Marshall acoplavam os dois campos na Política Externa dos Estados Unidos. Entretanto, embora conectadas por preocupações geopolíticas, não havia articulação explícita entre as duas áreas, e as preocupações eram projetadas de maneira distinta em termos discursivos e práticos (Hettne, 2010). Em outras palavras, embora tangentes de alguma maneira, a relação entre desenvolvimento e segurança internacional não se traduzia em um nexo, compreendido como uma "rede de conexões entre ideias, processos ou objetos díspares... implicando em um sem número de vínculos e relações" (Stern e Öjendal, 2010:11).

Em sua face acadêmica, o nexo atual é, em parte, resultado da transformação dos termos desenvolvimento e segurança internacional na década de 1990 (Chandler, 2007). Por um lado, o desenvolvimento passou a incorporar novos elementos para além do crescimento econômico, como a desigualdade social e a qualidade da vida humana (Sen, 1993). Por outro lado, redefiniu-se o campo da segurança incorporando outros atores para além do Estado, e levantaram novas questões relativas ao meio ambiente, à economia e à sociedade (Villa, 1994), o que, em efeito, fez com que preocupações antes estritamente ligadas ao desenvolvimento passassem a ser parte importante dos estudos em Segurança Internacional, e vice-versa (Duffield, 2001). A exemplo, tem-se os estudos de Collier e Hoeffler (1998) sobre as causas econômicas de guerras civis e de Ammons (1996) sobre as consequências da guerra para o desenvolvimento econômico.

Em termos práticos, segurança passou a ser instrumento para o desenvolvimento da mesma maneira que a promoção do desenvolvimento passou a ser garantia de segurança (Beall, Goodfellow e Putzel, 2006). Isso é observado não apenas nos discursos de lideranças globais, como também em políticas concretas promovidas por uma miríade de atores (Estados, organizações internacionais, organizações não governamentais, empresas multinacionais, indivíduos, etc.) que passaram a atuar paralelamente em tarefas ligadas ao desenvolvimento econômico e à segurança internacional - como a promoção de infraestrutura, edu- 
cação, saúde e saneamento básico e a resolução de conflitos (Abdenur e Neto, 2014; Buur, Jensen e Stepputat, 2007). Isso significa que a coordenação para atuação política em desenvolvimento e segurança internacional, antes realizada de forma separada ou tangencial, passou agora a sobrepor-se em diferentes níveis (Chandler, 2007).

É importante destacar que o nexo desenvolvimento-segurança internacional também tem sido alvo de intensas críticas. Argumenta-se que a discussão ganhou proeminência mais por preocupações securitárias do Norte, do que por demanda dos países do Sul (Chandler, 2007). Isso significa dizer que, que da perspectiva do norte global, o subdesenvolvimento e a fragilidade estatal do sul global teriam se tornado uma ameaça, sendo assim um elemento causal para os conflitos armados, o crime organizado internacional e o terrorismo transnacional (Brow e Gravingholt, 2016). Por este ângulo, tem-se que nas últimas décadas desenrolou-se um processo de securitização do desenvolvimento, sendo o progresso do mundo em desenvolvimento posto como vital para a garantia da segurança do mundo desenvolvido (Beall, Goodfellow e Putzel, 2006). Em consequência, não só a segurança teria prioridade sobre o desenvolvimento, como haveria de se perguntar: "segurança para quem?".

Outrossim, se analisa também até que ponto a ênfase no nexo segurança-desenvolvimento não representa um modo de legitimar novas formas de intervencionismo do norte em Estados do sul global (Brow e Gravingholt, 2016). Duffield $(2001,2007)$, por exemplo, aponta para esse fato ao estudar a noção de "paz liberal", incorporada às missões de paz contemporâneas. Para o autor, ela reflete um consenso existente de que os conflitos do sul devem ser abordados a partir de medidas que visem a construção de instituições democráticas e o funcionamento da economia de mercado (Duffield, 2001). Ao fim e ao cabo, isso possibilitaria "a transformação de sociedades disfuncionais marcadas pelo conflito em entidades cooperativas e estáveis" que não representam risco ao progresso do norte global (Duffield, 2001:11). No caso do BRICS, tais questões se articulariam em um contexto de crescente projeção internacional do bloco também na área de segurança internacional, incorporando cada vez mais em sua agenda aspectos dessa área. Em suma, é nesse contexto mais amplo do debate acerca da relação entre desenvolvimento e segurança que avançaremos na discussão a respeito da agenda do BRICS, buscando identificar possíveis pontos de articulação entre o objeto e as discussões teórico-conceituais. 


\section{Desenvolvimento e Segurança Internacional no BRICS}

A crise global que se expressa nos últimos anos e suas consequências políticas, econômicas e sociais, a falta de liderança mundial, a chamada ao multilateralismo e a alçada dos países emergentes tanto em âmbito do desenvolvimento quanto da segurança internacional, abriram o caminho para a discussão da maneira pela qual o nexo é concebido e praticado pelo BRICS (Abdenur e Neto, 2014). Embora o grupo tenha surgido a partir de um acrônimo que se originou no mercado financeiro, e focado em seus primeiros anos a dar conta dos efeitos perversos da crise econômica de 2008, o BRICS assumiu ao longo do tempo funções e características que sobrepujam sua própria origem (Ramos et al., 2018). Ao aspirar maiores ares dentro do sistema, buscam não só coordenar políticas e influenciar desdobramentos no campo do desenvolvimento, como também cooperar e estender sua presença em matéria de segurança internacional (Abdenur, 2017; Medeiros, Ribeiro e de Lyra, 2017). Isso pode ser visto, por exemplo, na crescente participação de países como Brasil, China ${ }^{2}$, Índia ${ }^{3}$ e África do Sul $^{4}$ no sistema global de governança em segurança internacional nos últimos anos - a despeito de certos revezes individuais na conjuntura contemporânea, particularmente com relação ao caso brasileiro.

De fato, a esfera econômica dominou as discussões e políticas do BRICS em seus primeiros anos de existência. Isso pode ser observado nos Gráficos 1 e 2, que comparam o número de citações da palavra "desenvolvimento" com as das palavras "paz" e "segurança" entre os anos de 2009 e 2010. Isso é explicado, em partes, pelo fato de a área temática ser um caminho de menor resistência para a cooperação, na medida em que as preferências e os interesses ali são mais ou menos convergentes entre os cinco países. Em contraste, Abdenur (2017) destaca, dentre outros pontos, os fatos de o grupo não se caracterizar como uma aliança de defesa, de ter sido criado recentemente, de ser uma entidade transregional na qual os Estados estão inseridos em contextos geopolíticos vastos e de não possuírem o mesmo status dentro do CSNU, como fatores importantes para se compreender alguns dos desafios para a cooperação em segurança internacional dentro do BRICS.

Apesar de não ser um caminho de menor resistência, desde a cúpula de Sanya, em 2011, as discussões e a coordenação política em segurança tem sido objeto crescente dentro do grupo (Ramos et al., 2018). Sanya talvez tenha sido ponto fulcral para tanto, na medida em que naquele momento 
os cinco Estados estavam presentes no CSNU - o que por certo facilitou a aproximação do grupo à área. Isso pode ser observado no índice de referência a "desenvolvimento", "paz" e "segurança" daquele ano $(1,73)$, que foi relevantemente menor se comparado aos 3,2 do ano anterior (ver Gráficos 1 e 2). Igualmente, por ser em Sanya também a primeira vez em que a cooperação em paz e segurança foi declarada como objetivo do grupo para além de desenvolvimento (\$3). Isso se repete em todas as outras declarações subsequentes: Delhi, 2012 (§3); Durban, 2013 (\$1 e §22); Fortaleza, 2014 (§4); Ufa, 2015 (§1); Goa, 2016 (§2); Xiamen, 2017 (§2); Joanesburgo, 2018 (§4); e Brasília, 2019 (§2).

\section{Gráfico 1}

Evolução da Relação de Menções a "Desenvolvimento" por Menções a "Paz" e

“Segurança Internacional” nas Declarações de Cúpula do BRICS, 2009-2019

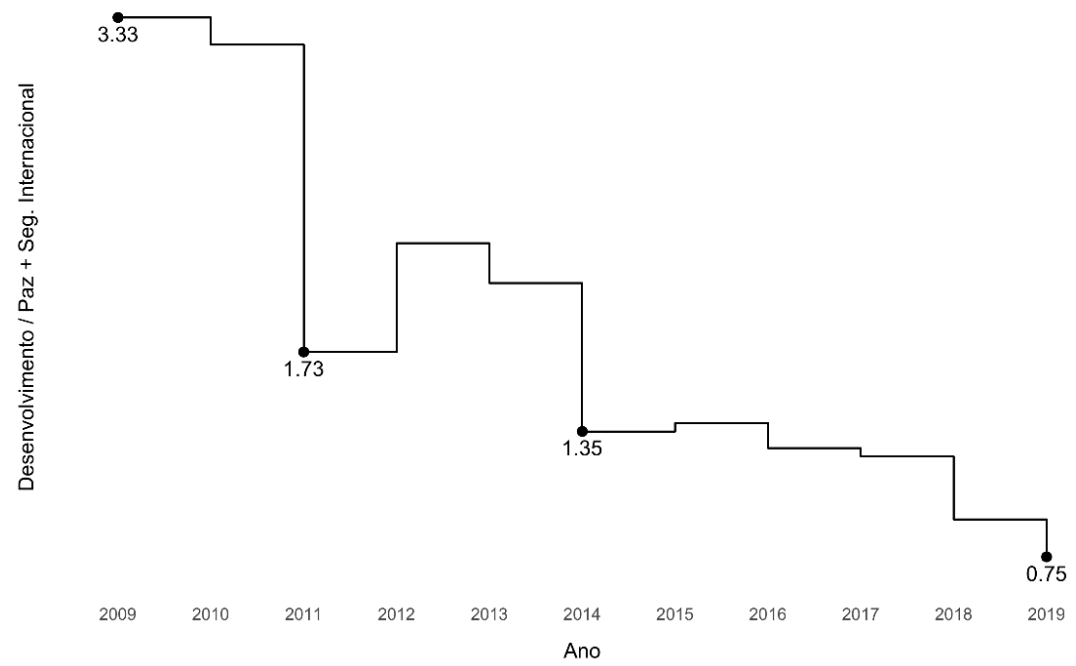

Fonte: Elaboração própria a partir de dados coletados pelos autores por meio de análise de conteúdo das declarações de cúpula do BRICS (2009-2019).

Tabela 1

Contagem das Palavras "Desenvolvimento", "Paz" e "Segurança" nas Declarações de Cúpula do BRICS (2009-2019)

\begin{tabular}{lccccccccccc}
\hline & 2009 & 2010 & 2011 & 2012 & 2013 & 2014 & 2015 & 2016 & 2017 & 2018 & 2019 \\
\hline $\begin{array}{l}\text { Desenvolvi- } \\
\text { mento }\end{array}$ & 10 & 16 & 26 & 45 & 64 & 74 & 96 & 60 & 79 & 59 & 30 \\
\hline $\begin{array}{l}\text { Paze Seg. } \\
\text { Int. }\end{array}$ & 3 & 5 & 15 & 20 & 31 & 55 & 69 & 47 & 64 & 63 & 41 \\
\hline
\end{tabular}

Fonte: Elaboração própria a partir de dados coletados pelos autores por meio de análise de conteúdo das declarações de cúpula do BRICS (2009-2019). 
Em termos do nexo desenvolvimento-segurança internacional, apesar de implícito em meio às discussões, foi somente na cúpula de Fortaleza, em 2014, que foi feita referência direta ao fato das áreas temáticas estarem "intimamente ligadas, se reforçarem mutualmente e serem chave para atingir uma paz sustentável" (§26). Declaração que se repete em Ufa, 2015 (\$9), Goa, 2016 (§8) e Xiamen, 2017 (\$38). Paralelamente à referência direta ao nexo, a área de segurança, que já vinha ocupando espaço considerável dentro das reuniões de cúpula, passou a ser cada vez mais relevante - tanto por esse motivo quanto por interesses e objetivos específicos de membros particulares do BRICS. Em 2014, o índice "desenvolvimento" / "paz" e "segurança" foi de 1,35 - o menor até aquele momento - e está em queda contínua desde então. Em Joanesburgo (2018), pela primeira vez, foram feitas mais referências a "paz" e "segurança" (63) do que a "desenvolvimento" (59). Isso se repetiu em Brasília (2019), onde foi registrada mais uma queda no índice, que chegou a 0,75 . De fato, portanto, tem-se que segurança internacional tornou-se área temática essencial para se compreender a cooperação dentro do BRICS, o que torna mister desvendar as esferas de coordenação política e as ações conjuntas concretas do grupo neste campo.

\section{APONTAMENTOS METODOLÓGICOS}

Na busca pela realização do objetivo inicialmente exposto, foi realizada uma análise de conteúdo das declarações finais relativas aos encontros anuais do BRICS. Os documentos analisados foram as declarações finais das reuniões de cúpula do BRICS ${ }^{6}$. Essas declarações fornecem dados primários, na forma de um resumo documental completo, a respeito da posição do grupo sobre os temas tratados anualmente e da maneira pela qual se decidiu agir conjuntamente frente a eles. Para analisá-las foi utilizado o software MAXQDA, próprio para exame de dados documentais. Acredita-se que seu uso propiciou acelerar as atividades operacionais (codificação e coleta dos dados), aumentar o rigor da análise e facilitar a reprodução dos resultados (Oliveira et al., 2016).

O processo de construção das categorias de análise se deu por procedimento indutivo. Isso significa que elas não estavam previamente estabelecidas, sendo resultado de uma "classificação analógica e progressiva dos elementos" (Bardin, 2016:149). O critério utilizado na categorização foi semântico (por temas) (Bardin, 2016). As unidades temáticas que compõe as categorias de análise são: Terrorismo; Segurança Cibernética; Tráfico de Drogas e Crime Organizado Transnacio- 
nal; Corrupção e Lavagem de Dinheiro; Paz e Resolução de Conflitos; Desarmamento e Não Proliferação de Armas de Destruição em Massa. Para criar as categorias de análise buscamos por áreas temáticas que representassem tópicos de discussão que, embora parte do mesmo guarda-chuva - segurança internacional -, contemplassem tipos diferentes de problema para o BRICS. Quando possível, foram criadas subcategorias de análise, tendo em vista a melhor representação do conteúdo das declarações. Elas permitiram identificar especificamente quais as regiões são destacadas como as mais instáveis para o BRICS e a quais conflitos e operações de paz o grupo dá maior atenção.

Quadro 1

Categorias de Análise

\begin{tabular}{ll}
\hline Categorias & Subcategorias \\
\hline Terrorismo & $\bullet$ Países \\
& $\begin{array}{l}\text { • Grupos } \\
\text { • FATF Int. Standards - Combate ao finan- } \\
\text { ciamento de atividades terroristas }\end{array}$ \\
\hline Segurança Cibernética & $\begin{array}{l}\text { • Crimes cibernéticos } \\
\bullet\end{array}$ \\
\hline Tráfico de Drogas - Terrorismo \\
cional
\end{tabular}

Fonte: Elaboração própria.

A análise se deu em termos quantitativos e qualitativos. Em termos quantitativos, foi criado um índice de menções únicas ao termo "desenvolvimento" por menções únicas aos termos "paz" e "segurança internacional" que permitiu comparar em cada cúpula a importância relativa dada aos eixos (desenvolvimento e paz e segurança internacional) pelo BRICS. Ele foi calculado pela divisão dos dois valores (quantidade de menções a "desenvolvimento" quantidade de menções à "paz" 
+ "segurança internacional"). Além disso, foram calculados quantos parágrafos em cada cúpula fazem menção a cada uma das categorias e subcategorias de análise criadas. Isso permitiu identificar as áreas temáticas mais importantes para o BRICS. Quanto maior o número de parágrafos relativos a determinada categoria e/ou subcategoria, mais importante foi considerado aquele assunto. De maneira a complementar a análise quantitativa, foi adotada como critério qualitativo para avaliar a importância de determinada área temática a existência ou ausência de Grupos de Trabalho (GTs) relativos a ela. De caráter técnico, os GTs são responsáveis dentro do BRICS por investigar de forma aprofundada determinados temas e, embora sem subordinação formal, reportar as recomendações diretamente aos altos representantes encarregados por temas de segurança (National Security Advisors - NSAs). Dessa maneira, constituem indicador relevante das áreas de maior interesse, pois quando presentes há maiores chances de concretização de políticas conjuntas do grupo relativas a elas.

\section{SEGURANÇA INTERNACIONAL: ÁREAS TEMÁTICAS E EVOLUÇÃO DAS DISCUSSÕES}

Em termos concretos, a cooperação do BRICS em segurança internacional foi de fato iniciada somente quando os cinco países estiveram presentes no CSNU, em 2011. Isso pode ser observado no Gráfico 1, onde se percebe que, em 2011, o índice de citações de desenvolvimento por "paz e segurança" caiu bruscamente pela primeira vez, marcando 1,73. Desde então sua regressão se dá progressivamente, tendo marcado 0,75 em 2019. Da mesma forma, naquele ano nota-se a incorporação de novas áreas temáticas para além do Terrorismo, como Paz e Resolução de Conflitos e Segurança Cibernética (ver Tabela 1). Esse padrão se repete nos anos seguintes, pela inclusão em 2012 de discussões sobre Tráfico de Drogas e Crime Organizado Internacional e Desarmamento e Não Proliferação; e, em 2014, de Corrupção e Lavagem de Dinheiro (ver Tabela 1). Portanto, mesmo não estando de fato institucionalizada de forma organizacional ${ }^{7}$, a cooperação em segurança internacional é hoje parte central das preocupações e atividades do BRICS (Abdenur, 2017).

A área temática Paz e Resolução de Conflitos aparece com destaque entre as declarações de cúpula, estando presente em 66 parágrafos desde 2009. É seguida em número de citações por Terrorismo (44), Desarmamento e Não Proliferação de Armas de Destruição em Massa 
(26), Segurança Cibernética (16), Tráfico de Drogas e Crime Organização Transnacional (14) e Corrupção e Lavagem de Dinheiro (10) (ver Gráfico 2). Entretanto, apesar de quantitativamente ser a principal área temática das declarações, em termos qualitativos não apresenta tanto destaque. Isso porque não há, de fato, coordenação política entre o grupo para lidar com questões relativas à área, mas sim um posicionamento conjunto acerca dos problemas. O que significa dizer que não há formulação de políticas conjuntas concretas que possam resolver os conflitos, mas somente recomendações. Esse cenário pode ser explicado pelo fato de o BRICS não ser uma aliança de defesa, de não ter o mesmo status no Conselho de Segurança e de os países membros possuírem interesses geopolíticos distintos (Abdenur, 2017).

Tabela 2

Frequência (N/\%) das Categorias de Análise em Parágrafos das Declarações de Cúpula do BRICS (2009-2019)

\begin{tabular}{|c|c|c|c|c|c|c|c|c|c|c|c|}
\hline & 2009 & 2010 & 2011 & 2012 & 2013 & 2014 & 2015 & 2016 & 2017 & 2018 & 2019 \\
\hline $\begin{array}{l}\text { Paz e } \\
\text { Resolução de } \\
\text { Conflitos }\end{array}$ & - & - & $\begin{array}{c}1 \\
33,3 \%\end{array}$ & $\begin{array}{c}4 \\
50 \%\end{array}$ & $\begin{array}{c}7 \\
58 \%\end{array}$ & $\begin{array}{c}12 \\
42,9 \%\end{array}$ & $\begin{array}{c}12 \\
37,5 \%\end{array}$ & $\begin{array}{c}7 \\
28 \%\end{array}$ & $\begin{array}{c}6 \\
30 \%\end{array}$ & $\begin{array}{c}8 \\
34,8 \%\end{array}$ & $\begin{array}{c}9 \\
40,9 \%\end{array}$ \\
\hline Terrorismo & $\begin{array}{c}1 \\
100 \%\end{array}$ & $\begin{array}{c}2 \\
100 \%\end{array}$ & $\begin{array}{c}1 \\
33,3 \%\end{array}$ & $\begin{array}{c}2 \\
25 \%\end{array}$ & $\begin{array}{c}2 \\
16,6 \%\end{array}$ & $\begin{array}{c}4 \\
14,3 \%\end{array}$ & $\begin{array}{c}7 \\
21,8 \%\end{array}$ & $\begin{array}{c}9 \\
36 \%\end{array}$ & $\begin{array}{c}5 \\
25 \%\end{array}$ & $\begin{array}{c}6 \\
26 \%\end{array}$ & $\begin{array}{c}5 \\
22,7 \%\end{array}$ \\
\hline $\begin{array}{l}\text { Desarma- } \\
\text { mento e Não } \\
\text { proliferação }\end{array}$ & - & - & - & $\begin{array}{c}1 \\
12,5 \%\end{array}$ & $\begin{array}{c}1 \\
8,3 \%\end{array}$ & $\begin{array}{c}4 \\
14,3 \%\end{array}$ & $\begin{array}{c}5 \\
15,6 \%\end{array}$ & $\begin{array}{c}2 \\
8 \%\end{array}$ & $\begin{array}{c}4 \\
20 \%\end{array}$ & $\begin{array}{c}5 \\
21,7 \%\end{array}$ & $\begin{array}{c}4 \\
18,1 \%\end{array}$ \\
\hline $\begin{array}{l}\text { Segurança } \\
\text { Cibernética }\end{array}$ & - & - & $\begin{array}{c}1 \\
33,3 \% \\
\end{array}$ & - & $\begin{array}{c}1 \\
8,3 \% \\
\end{array}$ & $\begin{array}{c}3 \\
10,7 \% \\
\end{array}$ & $\begin{array}{c}2 \\
6,3 \% \\
\end{array}$ & $\begin{array}{c}3 \\
12 \% \\
\end{array}$ & $\begin{array}{c}2 \\
10 \% \\
\end{array}$ & $\begin{array}{c}2 \\
8,7 \% \\
\end{array}$ & $\begin{array}{c}2 \\
9,1 \% \\
\end{array}$ \\
\hline $\begin{array}{l}\text { Tráfico de } \\
\text { Drogas } \\
\text { e Crime } \\
\text { Organizado } \\
\text { Transna- } \\
\text { cional }\end{array}$ & - & - & - & $\begin{array}{c}1 \\
12,5 \%\end{array}$ & $\begin{array}{c}1 \\
8,3 \%\end{array}$ & $\begin{array}{c}4 \\
14,3 \%\end{array}$ & $\begin{array}{c}4 \\
12,6 \%\end{array}$ & $\begin{array}{c}2 \\
8 \%\end{array}$ & $\begin{array}{c}2 \\
10 \%\end{array}$ & - & - \\
\hline $\begin{array}{l}\text { Corrupção e } \\
\text { Lavagem de } \\
\text { Dinheiro }\end{array}$ & - & - & - & - & - & $\begin{array}{c}1 \\
3,6 \%\end{array}$ & $\begin{array}{c}2 \\
6,3 \%\end{array}$ & $\begin{array}{c}2 \\
8 \%\end{array}$ & $\begin{array}{c}1 \\
5 \%\end{array}$ & $\begin{array}{c}2 \\
8,7 \%\end{array}$ & $\begin{array}{c}2 \\
9,1 \%\end{array}$ \\
\hline Total & 1 & 2 & 3 & 8 & 12 & 28 & 32 & 25 & 20 & 23 & 22 \\
\hline
\end{tabular}

Fonte: Elaboração própria a partir de dados coletados pelos autores por meio de análise de conteúdo das declarações de cúpula do BRICS (2009-2019). 
Gráfico 2

Frequência (N) das Categorias de Análise em Parágrafos das Declarações de Cúpula do BRICS (2009-2019)

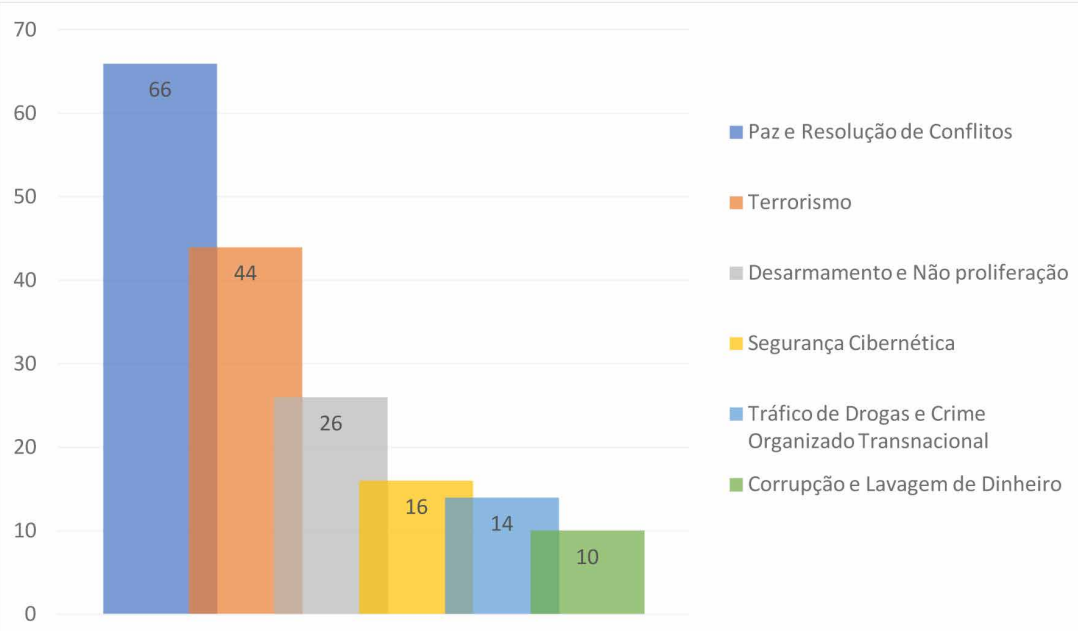

Fonte: Elaboração própria a partir de dados coletados pelos autores por meio de análise de conteúdo das declarações de cúpula do BRICS (2009-2019).

Em relação aos grupos de trabalho, há em meio ao BRICS quatro GTs relacionados à segurança internacional: i) GT Antiterrorismo (GTAT); ii) GT sobre Segurança no Uso das Tecnologias de Informação e Comunicação (GTTICs); iii) GT Antidrogas (GTAD); iv) GT Anticorrupção (GTAC). Tais grupos se relacionam diretamente a quatro das áreas temáticas destacadas neste trabalho, respectivamente: Terrorismo; Segurança Cibernética; Tráfico de Drogas e Crime Organizado Transnacional; e Corrupção e Lavagem de Dinheiro. Em termos substantivos, portanto, há de fato uma maior propensão à coordenação política nessas áreas do que em Paz e Resolução de Conflitos ou Desarmamento e Não Proliferação de Armas de Destruição em Massa, que não possuem GTs.

Isso não significa que a presença dos GTs de trabalho não impactou na intensificação, em termos quantitativos, da presença das áreas temáticas nas declarações. Por exemplo, nota-se que a partir da criação do GTAD e do GTTICs, em 2014, o número de parágrafos contendo temas relacionados respectivamente a Tráfico de Drogas e Crime Organizado Transnacional e Segurança Cibernética mais do que dobrou, padrão que se repete tanto em relação à Corrupção e Lavagem de Dinheiro, desde a criação do GTAC em 2015, quanto ao Terrorismo, desde o 
surgimento do GTAT em 2016. Isso pode ser percebido ao se observar a porcentagem, desde 2016, de parágrafos relativos à área temática quando comparada às outras esferas (ver Tabela 2).

\section{Paz e Resolução de Conflitos}

A área temática "Paz e Resolução de Conflitos" é, em termos quantitativos, a mais presente nas declarações de cúpula do BRICS desde sua primeira aparição, em 2011 (ver Tabela 1). Entretanto, não há GT relativo ao tema. Em termos qualitativos não há de fato cooperação substantiva dentro do grupo, havendo em grande medida não mais que acertos de posições e recomendações aos estados membro no tocante aos problemas identificados. Ao contrário de organizações regionais como a União Africana ${ }^{8}$ (UA), o BRICS não adota de forma multilateral métodos diretos de prevenção/resolução de conflitos. Isto é, não envia missões de observação e monitoramento on-site ou comissões de inquérito; não adota sanções diplomáticas, econômicas ou morais; e tampouco participa como grupo em processos de paz. Isso pode ser explicado pelas características próprias do BRICS enquanto organismo, o que dificulta a tradução da posição do grupo em práticas políticas multilaterais concretas (Abdenur, 2017).

Com relação aos parágrafos relativos à Paz e Resolução de Conflitos, apesar da prevalência de Conflitos Internos (50 aparições) em contraponto a Operações de Paz e Instabilidade Regional (11 aparições cada), destaca-se que as três áreas estão intimamente conectadas e são complementares (ver Tabela 3). Ou seja: são nas regiões citadas como instáveis que primordialmente se localizam os conflitos internos para os quais as declarações chamam atenção. Por sua vez, as operações de paz abrangidas remetem a conflitos internos mencionados previamente (ver Tabela 5). 
Tabela 3

Frequência (N) das Subcategorias de "Paz e Resolução de Conflitos" em Parágrafos das Declarações de Cúpula do BRICS (2009-2019)

\begin{tabular}{lcccccccccccc}
\hline & 2009 & 2010 & 2011 & 2012 & 2013 & 2014 & 2015 & 2016 & 2017 & 2018 & 2019 & Total \\
\hline $\begin{array}{l}\text { Instabilidade } \\
\text { Regional }\end{array}$ & - & - & - & 1 & 1 & 1 & - & 3 & 1 & 2 & 2 & 11 \\
\hline $\begin{array}{l}\text { Conflitos } \\
\text { Internos }\end{array}$ & - & - & 1 & 3 & 6 & 9 & 11 & 3 & 5 & 6 & 6 & 50 \\
\hline $\begin{array}{l}\text { Operações de } \\
\text { Paz }\end{array}$ & - & - & - & - & - & 4 & 4 & 1 & 1 & 1 & - & 11 \\
\hline $\begin{array}{l}\text { Paze } \\
\text { Resolução de } \\
\text { Conflitos }\end{array}$ & - & - & 1 & 4 & 7 & 12 & 12 & 7 & 6 & 8 & 9 & \\
\hline
\end{tabular}

Fonte: Elaboração própria a partir de dados coletados pelos autores por meio de análise de conteúdo das declarações de cúpula do BRICS (2009-2019).

\section{Tabela 4}

Frequência (N) das Regiões que Compõe a Subcategoria "Instabilidade Regional" em Parágrafos das Declarações de Cúpula do BRICS (2009-2019)

\begin{tabular}{lcccccccccccc}
\hline & 2009 & 2010 & 2011 & 2012 & 2013 & 2014 & 2015 & 2016 & 2017 & 2018 & 2019 & Total \\
\hline África & - & - & - & - & - & 1 & - & 2 & - & - & - & 3 \\
\hline $\begin{array}{l}\text { Norte da } \\
\text { África, Sahel } \\
\text { e Golfo da }\end{array}$ & - & - & - & - & 1 & - & - & - & - & - & - & 1 \\
\begin{tabular}{l} 
Guiné \\
\hline $\begin{array}{l}\text { Oriente Mé- } \\
\text { dio e Norte } \\
\text { da África }\end{array}$
\end{tabular} & - & - & - & 1 & - & - & - & 1 & - & - & - & 2 \\
\hline $\begin{array}{l}\text { Oriente } \\
\text { Médio }\end{array}$ & - & - & - & - & - & - & - & - & - & 1 & - & 1 \\
\hline $\begin{array}{l}\text { Golfo Pérsico } \\
-\end{array}$ & - & - & - & - & - & - & - & 1 & 1 & 1 & 3 \\
\hline $\begin{array}{l}\text { Nordeste } \\
\text { Asiático }\end{array}$ & - & - & - & - & - & - & - & - & - & - & 1 & 1 \\
\hline Total & - & - & - & 1 & 1 & 1 & - & 3 & 1 & 2 & 2 & \\
\hline
\end{tabular}

Fonte: Elaboração própria a partir de dados coletados pelos autores por meio de análise de conteúdo das declarações de cúpula do BRICS (2009-2019). 
Tabela 5

Frequência (N) dos Conflitos que Compõe a Subcategoria "Conflitos Internos" em Parágrafos das Declarações de Cúpula do BRICS (2009-2019)

\begin{tabular}{|c|c|c|c|c|c|c|c|c|c|c|c|c|}
\hline & 2009 & 2010 & 2011 & 2012 & 2013 & 2014 & 2015 & 2016 & 2017 & 2018 & 2019 & Total \\
\hline Afeganistão & - & - & - & 1 & 1 & 1 & 1 & 1 & 1 & 1 & 1 & 8 \\
\hline Burundi & - & - & - & - & - & - & 1 & - & - & - & - & 1 \\
\hline Iraque & - & - & - & - & - & 1 & 1 & - & 1 & - & - & 3 \\
\hline $\begin{array}{l}\text { Israel-Pales- } \\
\text { tina }\end{array}$ & - & - & - & 1 & 1 & 1 & 1 & 1 & 1 & 3 & 1 & 10 \\
\hline Líbia & - & - & 1 & - & - & - & 1 & - & 1 & - & 1 & 4 \\
\hline Mali & - & - & - & - & 1 & $1^{*}$ & $1^{*}$ & - & - & - & - & 3 \\
\hline $\begin{array}{l}\text { República } \\
\text { Centro Afri- } \\
\text { cana (RCA) }\end{array}$ & - & - & - & - & 1 & $1^{*}$ & 1 & - & 1 & - & - & 4 \\
\hline
\end{tabular}

República
Democrática
do Congo
(RCD)

\begin{tabular}{|c|c|c|c|c|c|c|c|c|c|c|c|c|}
\hline $\begin{array}{l}\text { Saara Oci- } \\
\text { dental }\end{array}$ & - & - & - & - & - & - & - & - & 1 & - & - & 1 \\
\hline Síria & - & - & - & 1 & 1 & 1 & - & 1 & 1 & 1 & 1 & 7 \\
\hline Somália & - & - & - & - & - & - & $1^{*}$ & - & 1 & - & - & 2 \\
\hline Sudão do Sul & - & - & - & - & - & $1^{*}$ & $1^{*}$ & - & 1 & - & 1 & 4 \\
\hline Ucrânia & - & - & - & - & 1 & 1 & - & - & - & - & & 2 \\
\hline Iêmen & - & - & - & - & - & - & - & - & 1 & 1 & & 3 \\
\hline Total & - & - & 1 & 3 & 6 & 9 & 11 & 3 & 5 & 6 & 6 & \\
\hline
\end{tabular}

*No mesmo ano, operação de paz relativa ao conflito foi citada: Mali - MINUSMA; RCA - MINUSCA; RCD-MONUSCO; Somália - AMISOM; Sudão do Sul - UNMISS.

Fonte: Elaboração própria a partir de dados coletados pelos autores por meio de análise de conteúdo das declarações de cúpula do BRICS (2009-2019).

Em relação ao eixo "Instabilidade Regional", a primeira aparição se deu em 2012. Desde então, todas as declarações, com exceção a de Ufa (2015), o citaram ao menos uma vez (ver Tabela 3). Em linhas gerais, o grupo demonstrou preocupação com a instabilidade na África e no Oriente Médio, enfatizando tanto questões humanitárias quanto relativas à segurança internacional (ver Tabela 4). Apesar de não adotar políticas concretas para lidar com a situação, em diversos momentos, 
como no parágrafo 30 da declaração de Fortaleza (2014), declarou suporte às ações desenvolvidas regionalmente para resolução dos conflitos, em especial às desenvolvidas pela UA no continente africano. Em relação à União Africana, por exemplo, o parágrafo 19 da declaração de Goa (2016) manifesta apoio ao estabelecimento de seu Fundo para Paz e à operacionalização da Força de Reserva Africana (African Standby Force, ASF).

No tocante aos "Conflitos Internos", há que se destacar que dos 14 conflitos citados desde Sanya (2011), todos estão localizados na África ou no Oriente Médio (7 e 6, respectivamente) - com a exceção de um conflito na Ucrânia (ver Tabela 5). Este último parece representar não uma preocupação conjunta dos cinco países, mas em especial os interesses da Rússia. Cabe destacar que sua presença se deu somente nas declarações de Durban (2013) e Fortaleza (2014), conseguintes ao início da crise no país após o anúncio pelo então presidente Viktor Yanukovych de suspender os preparativos para entrada na União Europeia (ver Tabela 4). Ao citar os conflitos, as declarações tendem a dar ênfase à solução pacífica das controvérsias, tendo como base os princípios do direito internacional e resoluções relevantes já adotadas pela Assembleia Geral e/ou o Conselho de Segurança das Nações Unidas. Isso pode ser observado, por exemplo, no parágrafo 38 da declaração de Fortaleza (2014), relativo ao conflito Israel-Palestina. No entanto, como já assinalado, o grupo não apresenta políticas multilaterais próprias e concretas para lidar com os conflitos citados nas declarações.

Dentre todos os conflitos, Israel-Palestina, Afeganistão e Síria destacam-se por serem os únicos países com presença constante desde Delhi (2012) e por apresentarem o maior número de citações em parágrafos das declarações, respectivamente 10, 8 e 7 (ver Tabela 4). Em relação ao conflito Israel-Palestina, o grupo recomenda uma resolução compreensiva e justa, baseada em resoluções das Nações Unidas sobre a questão. Além disso, incentiva as negociações diretas, a adoção de medidas para a reconstrução da confiança entre as partes e se opõe às medidas unilaterais e aos assentamentos israelenses na Cisjordânia. No Afeganistão, apoia aos comprometimentos internacionais relativos à situação no país anunciados na Conferência Internacional de Bonn (2011) e reitera o papel das Nações Unidas como sustentáculo para o processo de reconciliação nacional afegão e atenta para urgência da cooperação para que o país se estabilize em organismos regionais. Por fim, em relação à Síria, declara preocupação com as violações ao direito 
internacional humanitário e com denúncias de uso de armas químicas e biológicas no conflito. Entretanto, ao longo do tempo o grupo tendeu a se opor a qualquer tipo de intervenção militar externa que possa potencialmente ferir a soberania e a integridade territorial do país. Ademais, tem dado suporte a iniciativas não violentas para resolução do conflito propostas tanto pela Liga Árabe, quanto pelas Nações Unidas. Vê-se, portanto, que o BRICS de fato tende a não propor soluções concretas mesmo em conflitos mencionados de forma constante nas declarações , somente manifestando suporte a políticas propostas pelas Nações Unidas ou determinadas organizações regionais.

Por último, as Operações de Paz talvez sejam o único tema dentro da área de Paz e Conflito no qual se ensaia uma coordenação política concreta do grupo. De qualquer maneira, esses são desdobramentos recentes, na medida em que foi somente em Xiamen (2017) que se passou a reconhecer nas declarações a contribuição do BRICS para as operações de paz e a necessidade de comunicação e cooperação mais aprofundada no assunto. Mais recentemente, foi em Joanesburgo (2018) que a África do Sul propôs a criação de um GT responsável pela intensificação da coordenação política na matéria. Até Goa (2016), as declarações de cúpula haviam se restringido a declarar o suporte do grupo a determinadas operações de paz - como a Missão Multidimensional Integrada das Nações Unidas para a Estabilização do Mali (MINUSMA) e a Missão de Estabilização das Nações Unidas na República Democrática do Congo (MINUSCO) (ver Tabela 4).

\section{Terrorismo}

Dentre todas as áreas temáticas vinculadas à segurança internacional, Terrorismo talvez seja a mais tradicional dentro do grupo. É a única presente desde a primeira declaração, em 2009 (ver Tabela 2). E após Paz e Resolução de Conflitos é a que apresenta maior frequência nas declarações (44 parágrafos, ver Gráfico 2). A criação do GTAT, em 2016, contribuiu não só para a intensificar as citações ao tema, mas também para qualificar a cooperação operada dentro do grupo, tendo sido os anos subsequentes marcados pela apresentação das bases de aproximação à matéria. Para além das citações substantivas, foram identificadas três subáreas durante o processo de codificação: Grupos, Países e FAFT Int. Standards - estando as duas primeiras relacionadas às subáreas de Paz e Resolução de Conflitos (ver Tabelas 6, 7 e 8). 
Analisando qualitativamente as referências ao terrorismo dentro das declarações das cúpulas percebe-se, desde 2009, um aprofundamento paulatino em seus termos. A princípio, as menções condenavam o terrorismo em todas as suas formas e manifestações ${ }^{9}$; mas não apresentavam orientações concretas para lidar com o problema e não indicavam uma posição do grupo em relação a mecanismos internacionais de combate ao terror. Apesar de já em Ecaterimburgo (2009) ter-se feito nota ao rascunho da Convenção Compreensiva contra o Terrorismo Internacional (CCIT) que transitava em meio a AGNU, a declaração não afirmava inequivocadamente as Nações Unidas como lócus central para essas discussões. Isso passou a ser feito somente a partir de Sanya $(2011)^{10}$ - quando os cinco países estavam presentes no CSNU -, e tem se repetido desde então.

Dentro do BRICS, portanto, o primeiro grande movimento relativo à área foi a indicação do papel das Nações Unidas na coordenação de ações multilaterais contraterroristas e a necessidade de reforçar sua estrutura para lidar com o problema. Nesse sentido, o grupo suporta continuamente a implementação da estratégia global contraterrorista da AGNU e reforça a necessidade de observar as resoluções do CSNU sobre a questão. Esse processo chegou a seu ápice em Joanesburgo (2018), com a chamada, no parágrafo 34, para o estabelecimento de uma coalizão genuinamente global de combate ao terror sob os auspícios das Nações Unidas.

Tabela 6

Frequência (N) das Subcategorias de “Terrorismo" em Parágrafos das Declarações de Cúpula do BRICS (2009-2019)

\begin{tabular}{lcccccccccccc}
\hline & 2009 & 2010 & 2011 & 2012 & 2013 & 2014 & 2015 & 2016 & 2017 & 2018 & 2019 & Total \\
\hline Países & - & 1 & - & 1 & 1 & 2 & 4 & 2 & 1 & 1 & 2 & 15 \\
\hline Grupos & - & - & - & - & - & 1 & 5 & 1 & 1 & - & - & 8 \\
\hline $\begin{array}{l}\text { FATF - Int. } \\
\text { Standards }\end{array}$ & - & - & - & - & - & - & 1 & 1 & 1 & 1 & - & 4 \\
\hline Terrorismo & 1 & 2 & 1 & 2 & 2 & 4 & 7 & 9 & 5 & 6 & 5 & \\
\hline
\end{tabular}

Fonte: Elaboração própria a partir de dados coletados pelos autores por meio de análise de conteúdo das declarações de cúpula do BRICS (2009-2019). 
Tabela 7

Frequência (N) dos Estados que Compõe a Subcategoria "Países" em Parágrafos das Declarações de Cúpula do BRICS (2009-2019)

\begin{tabular}{lcccccccccccc}
\hline & 2009 & 2010 & 2011 & 2012 & 2013 & 2014 & 2015 & 2016 & 2017 & 2018 & 2019 & Total \\
\hline Afeganistão & - & - & - & 1 & 1 & 1 & 1 & 1 & 1 & - & 1 & 7 \\
\hline Índia & - & 1 & - & - & - & - & - & 1 & - & - & - & 2 \\
\hline Iraque & - & - & - & - & - & - & 1 & - & - & - & - & 1 \\
\hline Quênia & - & - & - & - & - & - & 1 & - & - & - & - & 1 \\
\hline Rússia & - & 1 & - & - & - & - & - & - & - & - & - & 1 \\
\hline Síria & - & - & - & - & - & 1 & 2 & - & - & - & 1 & 4 \\
\hline Total & - & 1 & - & 1 & 1 & 2 & 4 & 2 & 1 & 1 & 2 & \\
\hline
\end{tabular}

Fonte: Elaboração própria a partir de dados coletados pelos autores por meio de análise de conteúdo das declarações de cúpula do BRICS (2009-2019).

Tabela 8

Frequência (N) dos Grupos Terroristas que Compõe a Subcategoria “Grupos” em Parágrafos das Declarações de Cúpula do BRICS (2009-2019)

\begin{tabular}{lcccccccccccc}
\hline & 2009 & 2010 & 2011 & 2012 & 2013 & 2014 & 2015 & 2016 & 2017 & 2018 & 2019 & Total \\
\hline Al-Qaeda & - & - & - & - & - & 1 & - & - & 1 & - & - & 2 \\
\hline Al-Shabaab & - & - & - & - & - & - & 2 & - & - & - & - & 2 \\
\hline BokoHaram & - & - & - & - & - & 1 & 1 & - & - & - & - & 2 \\
\hline ISIS & - & - & - & - & - & - & 3 & 1 & 1 & - & - & 5 \\
\hline Jabhat-Al- & - & - & - & - & - & - & - & 1 & - & - & - & 1 \\
Nusra & - & - & - & - & - & - & - & - & 1 & - & - & 1 \\
\hline Talibã & - & - & - & - & - & 1 & 5 & 1 & 1 & - & - \\
\hline Total
\end{tabular}

Fonte: Elaboração própria a partir de dados coletados pelos autores por meio de análise de conteúdo das declarações de cúpula do BRICS (2009-2019).

Em termos de cooperação intragrupo, foi também em 2011 a primeira vez que o BRICS declarou estar disposto a intensificar sua coordenação política. Contudo, o tema retornou somente em 2014, quando se enfatizou, em especial, o combate preventivo ao financiamento e ao suporte de atividades terroristas. Como consequência, em 2015, pela primeira vez foi feita referência à necessidade de adotar as recomendações da FATF (Financial Action Task Force) relativas ao combate ao aporte financeiro a grupos terroristas. Desde então, essas referências estiveram presentes em todas as outras declarações (ver Tabela 6). 
Em todo caso, foi somente em 2016, quando o GT Antiterrorismo foi formado dentro do BRICS, que foram estabelecidas de forma clara as diretrizes para a coordenação política dos cinco países sobre a questão. Seguindo as linhas da CCIT, a partir de Goa (2016) o grupo adotou uma perspectiva mais compreensiva do tema. Isso significa que, na formulação de sua estratégia contraterrorista, se foca não somente no combate direto, mas principalmente em práticas políticas indiretas que visam dificultar as atividades dos grupos. Isso é planejado em coordenação com os outros GTs, como o GT Antidrogas e o GT Anticorrupção, buscando entraves a potenciais fontes de financiamento do crime organizado internacional e do tráfico de drogas, assim como o combate à corrupção e à lavagem de dinheiro. Da mesma forma, em articulação com GT sobre Segurança no uso das Tecnologias de Informação e Comunicação, são coordenadas práticas que visam conter potenciais ataques às redes computacionais de informação. As discussões para o desenvolvimento de estratégia contraterrorista conjunta do BRICS foram reforçadas na cúpula de Brasília (2019) por meio da criação de subgrupos temáticos e da realização de um seminário que visava pautar e intensificar a cooperação intragrupo no tópico.

No que se refere à subcategoria "Países", as primeiras declarações se restringiram a prestar solidariedade e condenar ataques ocorridos em Estados do grupo (ver Tabela 6). É o caso, por exemplo, do parágrafo 24 da declaração de Brasília (2010), que declara a simpatia e o repúdio do Brasil e da China aos atentados ocorridos na Índia e na Rússia. A partir de Delhi (2012), entretanto, o BRICS passou a citar nominalmente outros países e a clamar por cooperação internacional no combate ao terrorismo - em especial no Afeganistão e na Síria, que tiveram 7 e 4 aparições, respectivamente (ver Tabela 7). Nesses países, o terror é visto pelo grupo como potencial elemento disruptivo aos processos de paz e estabilidade. Isso conecta as preocupações sobre Terrorismo com as sobre Paz e Resolução de Conflitos - cabendo lembrar que, dentre os conflitos internos, os do Afeganistão e da Síria estão entre os mais citados (ver Tabela 5).

Por fim, de Fortaleza (2014) a Xiamen (2017), as declarações passaram também a fazer referências nominais a grupos terroristas, o que demonstra maior preocupação do BRICS com algumas organizações em específico. Destacam-se o ISIS, com referência em 5 parágrafos, e a al-Qaeda, o al-Shabaab e o Boko Haram, com 2 citações cada (ver Tabela 8). Na declaração de 2015, por exemplo, o parágrafo 42 com- 
preende as atividades do ISIS nas fronteiras do Afeganistão como fator de ameaça tanto à segurança e à paz em nível regional, quanto ao processo de reabilitação e reconstrução do país.

\section{Desarmamento e Não Proliferação}

Desarmamento e Não Proliferação de Armas de Destruição em Massa é a terceira área temática com maior presença nas declarações de cúpula do BRICS, tendo sido referenciada em 26 parágrafos (ver Gráfico 2) desde sua primeira aparição em 2012 (ver Tabela 2). Não há GT responsável por coordenar as discussões sobre o tema, e apesar do relativamente alto número de menções, a cooperação intra BRICS é dificultada pelo fato de não haver homogeneidade dentro do grupo em relação à posse de armamentos nucleares entre seus membros. Dessa maneira, o foco tende a recair a casos específicos de relevância internacional. Em termos substantivos, a coordenação política se dá somente no que concerne à não-proliferação no Espaço Sideral e às recomendações da FATF para o combate à proliferação de armas de destruição em massa entre atores não-estatais (ver Tabela 9).

Tabela 9

Frequência (N) das Subcategorias de "Desarmamento e Não Proliferação" em Parágrafos das Declarações de Cúpula do BRICS (2009-2019)

\begin{tabular}{lcccccccccccc}
\hline & 2009 & 2010 & 2011 & 2012 & 2013 & 2014 & 2015 & 2016 & 2017 & 2018 & 2019 & Total \\
\hline $\begin{array}{l}\text { Armas } \\
\text { Químicas }\end{array}$ & - & - & - & - & - & 1 & 1 & - & 1 & 1 & 1 & 5 \\
\hline $\begin{array}{l}\text { Armas } \\
\text { Nucleares }\end{array}$ & - & - & - & 1 & 1 & 2 & 2 & - & 2 & 2 & 1 & 11 \\
\hline $\begin{array}{l}\text { Armas } \\
\text { Biológicas }\end{array}$ & - & - & - & - & - & - & - & - & - & - & 1 & 1 \\
\hline $\begin{array}{l}\text { Espaço } \\
\text { Sideral }\end{array}$ & - & - & - & - & - & 1 & 1 & 1 & 1 & 1 & 1 & 6 \\
\hline $\begin{array}{l}\text { FATF Int. } \\
\text { Standards }\end{array}$ & - & - & - & - & - & - & 1 & 1 & - & 1 & - & 3 \\
\hline $\begin{array}{l}\text { Desarma- } \\
\text { mento e Não } \\
\text { proliferação }\end{array}$ & - & - & - & 1 & 1 & 4 & 5 & 2 & 4 & 5 & 4 & \\
\hline
\end{tabular}

Fonte: Elaboração própria a partir de dados coletados pelos autores por meio de análise de conteúdo das declarações de cúpula do BRICS (2009-2019). 
Em termos quantitativos, "Armas Nucleares" é a subcategoria com maior número de menções em parágrafos, 11 (ver Tabela 9). Entretanto, como antes assinalado, as referências dizem respeito a casos específicos de relevância internacional. Das 11 citações, cinco mencionam a crise do Irã e três a crise na península coreana. A proeminência do Irã nas declarações pode ser compreendida pelo importante papel da China e de seus enviados especiais durante as negociações do acordo nuclear, em 2015. Inclusive, o conteúdo dos parágrafos é próximo da posição chinesa sobre a questão (Kondapalli, 2016). O tema apareceu de forma contínua nos anos de 2012 (§22), 2013 (§28) e 2014 (§41), e foi retomado em 2017(§45) e 2018 (§47), quando Donald Trump foi eleito nos EUA e proferiu seus primeiros discursos contrários à implementação do acordo firmado (Abadi, 2018).

Da mesma sorte, quatro dos cinco parágrafos que fazem referência a "Armas Químicas" (ver Tabela 9) mencionam diretamente a crise na Síria. O momento de sua presença é importante na medida em que ocorre após o estabelecimento da "linha-vermelha", imposta por Obama a Assad no segundo semestre de 2013 (Lewis e Tertrais, 2017). Em resposta, nos anos subsequentes, 2014 (§37) e 2015 (§36), o BRICS condenou o uso de armas químicas na guerra civil e reiterou a necessidade da remoção e eliminação completa do estoque no país. Ao mesmo tempo, repudiou qualquer tipo de intervenção militar unilateral no conflito, referência que se tornou padrão e voltou a aparecer em 2017 (§41) e 2018 (§46). Em Brasília (2019), o grupo não mencionou o tema ligando-o à crise na Síria, mas declarou seu suporte à Organização para a Proibição de Armas Químicas (em inglês, OPCW) e à Convenção Sobre a Proibição do Desenvolvimento, Produção, Armazenagem e Utilização de Armas Químicas e Sobre a sua Destruição (em inglês, CWC). Da mesma maneira, foi também em 2019 a primeira vez, em dez anos, que o BRICS fez referência a armas biológicas (ver Tabela 9). Assim como no caso das armas químicas, o grupo advoga pela sua proibição (e não somente desarmamento e nãoproliferação, como no caso das armas nucleares), tendo como ponto de partida a Convenção Sobre a Proibição ao Desenvolvimento, Produção e Armazenagem de Armas Bacteriológicas ou Tóxicas e Sobre a sua Destruição (em inglês, BWC).

Por fim, embora apresentando somente seis referências diretas em parágrafos das declarações (ver Tabela 9), em termos qualitativos a coordenação política em torno de um Espaço Sideral livre de armamentos 
nucleares merece destaque. Trazida ao grupo por China e Rússia em 2014, a posição do BRICS é a de que a exploração do espaço sideral deve ter propósitos unicamente pacíficos e que a possibilidade de torná-lo lócus de confrontos militares e corridas armamentistas é uma ameaça grave à paz e à segurança internacional. O grupo entende a transparência como fundamental para lograr o objetivo e, nesse sentido, reconhece as Conferências Sobre Desarmamento como local para as negociações multilaterais em torno da questão - tendo China e Rússia apresentado conjuntamente, em 2014, o rascunho de um tratado sobre a questão. Enfim, em Joanesburgo (2018) e Brasília (2019) o BRICS declarou suporte ao grupo de especialistas para prevenção de corridas armamentistas no espaço sideral (em inglês, PAROS) e salientou sua posição de que qualquer instrumento relativo à matéria deverá ser não discriminatório em relação aos direitos de desenvolvimento de tecnologia para fins pacíficos.

\section{Segurança Cibernética}

Segurança cibernética é a quarta categoria com maior referência (16) dentro das declarações de cúpula do BRICS (ver Gráfico 2). Apesar de estar presente nas declarações desde Sanya (2011), foi somente após a criação do GTTICs, em 2015, que os esforços de coordenação política sobre o tema foram intensificados. Em termos comparativos, até 2013 a área havia sido aludida em somente 2 parágrafos, enquanto a média para os anos subsequentes foi de 2,3 parágrafos por declaração (ver Tabela 2). Foram identificadas duas subáreas relativas à segurança cibernética de interesse do BRICS. Uma delas, o combate a crimes cibernéticos, com cinco aparições em parágrafos, sendo a primeira em 2011 (ver Tabela 10). E a outra, a inter-relação entre as novas tecnologias da informação e comunicação (ICTs) e atividades terroristas, com sete aparições, tendo a primeira referência ocorrido em 2014 (ver Tabela 10).

Apesar de reconhecer o papel positivo das ICTs na promoção do desenvolvimento econômico, o BRICS passou a se preocupar ao longo do tempo em contribuir para a construção de um ciberespaço seguro. Isso seria fundamental para assegurar a defesa das infraestruturas críticas dos Estados, hoje amplamente conectadas em rede. Dois tipos de ameaça são levantados pelo grupo: o mal uso das ICTs por organizações criminosas e grupos terroristas (ver Tabela 10) e o mal uso de ICTs por parte dos Estados, seja violando o direito à privacidade de seus nacionais, influenciando assuntos domésticos de seus pares ou perpetuando ataques cibernéticos. De modo a combater tais problemas, em nível sis- 
têmico o BRICS reafirma a importância das Nações Unidas como lócus para o desenvolvimento de instrumento vinculante responsável por assegurar o uso pacífico, seguro e aberto das ICTs. Para tanto, destaca a importância dos trabalhos em torno do UNGGE (United Nations Group of Governmental Experts on Developments in the Field of Information and Telecommunications in the Context of International Security).

Tabela 10

Frequência (N) das Subcategorias de "Segurança Cibernética" em Parágrafos das Declarações de Cúpula do BRICS (2009-2019)

\begin{tabular}{lcccccccccccc}
\hline & 2009 & 2010 & 2011 & 2012 & 2013 & 2014 & 2015 & 2016 & 2017 & 2018 & 2019 & Total \\
\hline $\begin{array}{l}\text { Combate } \\
\begin{array}{l}\text { a crimes } \\
\text { cibernéticos }\end{array}\end{array}$ & - & - & 1 & - & - & 1 & - & - & 1 & 1 & 1 & 5 \\
\hline $\begin{array}{l}\text { ICTs-Terror- } \\
\text { ismo }\end{array}$ & - & - & - & - & - & 1 & - & 1 & 2 & 2 & 1 & 7 \\
\hline $\begin{array}{l}\text { Segurança } \\
\text { Cibernética }\end{array}$ & - & - & 1 & - & 1 & 3 & 2 & 3 & 2 & 2 & 2 & \\
\hline
\end{tabular}

Fonte: Elaboração própria a partir de dados coletados pelos autores por meio de análise de conteúdo das declarações de cúpula do BRICS (2009-2019).

Em termos de cooperação intra BRICS, foi somente a partir de Fortaleza (2014) que o grupo se comprometeu a trabalhar em conjunto no que tange à segurança cibernética. Tendo em vista esse objetivo, em Ufa (2015), a partir de proposta da Rússia, decidiu-se por criar o GTTICs. E já em Goa (2016) foi estabelecido o BRICS Roadmap of Practical Cooperation on Ensuring Security in the Use of ICTs, envolvendo, dentre outros tópicos, a possibilidade de estabelecer mecanismos de compartilhamento de informações sobre ciberameaças, tendo em vista mitigar potenciais riscos a infraestruturas críticas. Somente em Joanesburgo (2018), entretanto, foi que se fez referência à elaboração de um acordo intergovernamental baseado nos termos discutidos em meio ao GTTICs. Como desdobramento, em Brasília (2019) a Rússia oficialmente propôs um acordo intra BRICS, e o Brasil sugeriu a consecução de tratados bilaterais relativos à matéria.

\section{Tráfico de Drogas e Crime Organizado Transnacional}

A área temática de Tráfico de Drogas e Crime Organizado Internacional foi referenciada em 14 parágrafos (ver Gráfico 2) desde sua primeira aparição, em 2014. No entanto, foi deixada de lado nas duas 
últimas reuniões de cúpula (ver Tabela 2) - Joanesburgo (2018) e Brasília (2019). A área se divide em dois eixos temáticos que, mesmo inter-relacionados, exigem algum tipo de preocupação particular por parte do BRICS: i) Tráfico de Drogas e ii) Crime Organizado Transnacional. Dentre eles, em termos de cooperação intra BRICS, o segundo é o de mais intensa coordenação política, tendo em vista a criação do GTAD, em 2014. Destaca-se também a subcategoria Pirataria (ver Tabela 11).

Tabela 11

Frequência (N) das Subcategorias de "Tráfico de Drogas e Crime Organizado Transnacional” em Parágrafos das Declarações de Cúpula do BRICS (2009-2019)

$\begin{array}{llllllllllll}2009 & 2010 & 2011 & 2012 & 2013 & 2014 & 2015 & 2016 & 2017 & 2018 & 2019 & \text { Total }\end{array}$

\begin{tabular}{lllllllllllll}
\hline Pirataria & - & - & - & - & - & 1 & 1 & - & - & - & - & 2 \\
\hline Tráfico de & & & & & & & & & & & & \\
Drogas \\
e Crime \\
$\begin{array}{l}\text { Organizado } \\
\text { Transna- } \\
\text { cional }\end{array}$ & - & - & - & 1 & 1 & 4 & 4 & 2 & 2 & - & - \\
\hline
\end{tabular}

Fonte: Elaboração própria a partir de dados coletados pelos autores por meio de análise de conteúdo das declarações de cúpula do BRICS (2009-2019).

Em relação ao Tráfico de Drogas, as declarações apontam para seu efeito nocivo à estabilidade política e ao desenvolvimento sustentável como justificativa para lidar de forma imediata com o fenômeno. Para tanto, reiteram o comprometimento do grupo com uma política compreensiva, integrada e multidisciplinar baseada em convenções das Nações Unidas - como a Convenção Única Sobre Narcóticos (1961), a Convenção Relativa às Substâncias Psicotrópicas (1971), e a Convenção Contra o Tráfico Ilícito de Narcóticos e Substâncias Psicotrópicas (1988). No que se refere à cooperação intra BRICS, apesar dos poucos avanços e de não ter sido mencionada em Joanesburgo (2018), havia se decidido, em 2016, por criar no escopo do GTAD mecanismos de interação entre os cinco países para lidar de forma integrada com o problema. Nesse sentido, foi estabelecida cooperação entre as agências de controle de drogas de cada Estado. Enfim, há um foco grande, e em específico, no tráfico de drogas no Afeganistão - preocupação que compõe 6 dos 14 parágrafos nos quais a área temática está presente. O BRICS vê com apreensão o crescimento na produção de narcóticos nesse país e oferece suporte aos esforços internacionais para mitigar a questão no quadro do PPI (Paris Pact Initiative). 
No que concerne ao Crime Organizado Transnacional, desde Fortaleza (2014) as declarações afirmam ser objetivo do grupo a redução do impacto negativo do problema em uma perspectiva multinível. No entanto, apesar da chamada em Goa (2016) para uma maior coordenação política do BRICS nesse tópico, as declarações somente aludem à posição do grupo em relação às iniciativas multilaterais no âmbito das Nações Unidas. Em especial, reiteram o compromisso de cooperar para o estabelecimento da Prevenção Criminal como prioridade de longo prazo da ONU e de mecanismos de controle sobre a implementação da Convenção contra o Crime Organizado Transnacional (2000) e seus protocolos adicionais. Por fim, em relação à Pirataria, o BRICS reitera a necessidade de combater o problema de forma integrada e compreensiva e de estabelecer relatórios objetivos sobre áreas de alto risco.

\section{Corrupção e Lavagem de Dinheiro}

Corrupção e Lavagem de dinheiro é a área temática com menor número de menções (10) em parágrafos das declarações de cúpula (ver Gráfico 2), tendo aparecido pela primeira vez somente em 2014 (ver Tabela 2). Naquele ano, fez-se referência em específico à implementação da Convenção das Nações Unidas Contra a Corrupção (UNCAC). Entretanto, a partir da criação do GTAC, em Goa (2016), a coordenação política intra BRICS sobre o tema tem intensificado substantivamente. Há crescente compreensão dentro do grupo dos impactos negativos da corrupção e da lavagem dinheiro no desenvolvimento econômico, assim como de sua importância para o crime organizado transnacional e para o financiamento de atividades terroristas.

Tabela 12

Frequência (N) das Subcategorias de “Corrupção e Lavagem de Dinheiro" em Parágrafos das Declarações de Cúpula do BRICS (2009-2019)

\begin{tabular}{lcccccccccccc}
\hline & 2009 & 2010 & 2011 & 2012 & 2013 & 2014 & 2015 & 2016 & 2017 & 2018 & 2019 & Total \\
\hline $\begin{array}{l}\text { FATF - Int. } \\
\text { Standards }\end{array}$ & - & - & - & - & - & - & 1 & 1 & - & 1 & 1 & 4 \\
\hline $\begin{array}{l}\text { Corrupção e } \\
\text { Lavagem de } \\
\text { Dinheiro }\end{array}$ & - & - & - & - & - & 1 & 2 & 2 & 1 & 2 & 2 & 10 \\
\hline
\end{tabular}

Fonte: Elaboração própria a partir de dados coletados pelos autores por meio de análise de conteúdo das declarações de cúpula do BRICS (2009-2019). 
Como resultado das discussões, em Joanesburgo (2018) o grupo estabeleceu de maneira clara as práticas a serem implementadas conjuntamente visando combater a corrupção, o que é um passo além da adoção das recomendações do FATF e da cooperação dentro dos órgãos regionais da organização - os FSRBS (FATF - Style Regional Bodies) -, ponto com presença contínua nas declarações desde 2015 (ver Tabela 12). Nesse sentido, em 2018 foram estabelecidos mecanismos para cooperação na aplicação de leis anticorrupção, extradição de fugitivos e recuperação de ativos. Além disso, foi criada no BRICS uma plataforma para troca de experiências e exploração de convergências sobre o tema. Esses compromissos foram reafirmados em Brasília (2019), onde o grupo declarou que se posicionará conjuntamente em fóruns multilaterais como o G20 e enfatizou seu objetivo de intensificar a cooperação intra BRICS para recuperar ativos extraviados internacionalmente.

\section{CONSIDERAÇÕES FINAIS}

O artigo buscou analisar de forma aprofunda e detalhada a intensificação da cooperação em segurança internacional no BRICS. Mesmo não sendo um tema fundante do grupo, como é o caso das discussões relativas ao desenvolvimento internacional, a literatura recente aponta uma presença cada vez mais marcante da área temática da segurança internacional nas reuniões de cúpula ${ }^{11}$. Argumenta-se aqui que tal desdobramento não deve ser compreendido como alheio aos moldes originais do BRICS, na medida em que muitas vezes as áreas temáticas associadas à segurança internacional aparecerem com relevância na agenda do grupo em associação com a problemática do desenvolvimento. Contudo, nem sempre este é o caso. Na verdade, apesar de a relação estreita entre desenvolvimento e segurança ser explicitamente mencionada nas declarações de várias cúpulas, em termos concretos nota-se que essa relação, no caso do BRICS, não é tão unívoca. Como visto, muitas vezes as incorporações e avanços de discussões na área de segurança internacional ocorrem em função dos interesses particulares de seus países membros, que intentam, com o BRICS, dar uma maior projeção internacional aos seus interesses na área. Isso pode ser observado nos interesses regionais sul-africanos, no caso russo em relação à Ucrânia e nas preocupações russas, chinesas e indianas com o tema do combate ao terrorismo. Tudo isso ajuda a entender não apenas como algumas dessas questões entram na agenda no BRICS, mas também o porquê de em muitos casos a cooperação não avançar nos mesmos ter- 
mos que na área do desenvolvimento internacional. Em suma, embora seja possível perceber certo nexo segurança-desenvolvimento ao longo da história das cúpulas do BRICS, ponderações necessitam ser feitas.

Assim, embora não seja área de menor resistência, de fato nota-se a intensificação na quantidade das menções e na qualidade da coordenação política em segurança internacional no BRICS. Se, de fato, o ponto de partida é Sanya (2011), já em Joanesburgo (2018) os termos "Paz e Segurança" foram mencionados mais vezes na declaração de cúpula do que o termo "Desenvolvimento" (ver Gráfico 1). No entremeio, expandiram-se os eixos temáticos tratados pelo grupo (ver Tabela 1) e foram criados grupos de trabalho para lidar com alguns deles de forma mais contundente. Hoje, portanto, se destacam seis áreas temáticas principais: i) Terrorismo; ii) Segurança Cibernética; iii) Tráfico de Drogas e Crime Organizado Transnacional; iv) Corrupção e Lavagem de Dinheiro; v) Paz e Resolução de Conflitos; e vi) Desarmamento e Não Proliferação de Armas de Destruição em Massa. Destacam-se também quatro grupos de trabalho consolidados e um quinto em formação: i) GT Antiterrorismo (GTAT); ii) GT sobre Segurança no Uso das Tecnologias de Informação e Comunicação (GTTICs); iii) GT Antidrogas (GTAD); iv) GT Anticorrupção (GTAC); e o incipiente v) GT sobre Operações de Paz.

Dentre as áreas temáticas, em termos quantitativos, observou-se a área de Paz e Resolução de Conflitos como aquela com maior número de menções, seguida por Terrorismo. Entretanto, características próprias ao BRICS não favorecem a qualidade da coordenação política na primeira e, por isso, não há a construção de políticas concretas para a área além de recomendações e do estabelecimento de posição conjunta. Isso pode vir a mudar caso de fato seja construído o GT sobre Operações de Paz, após a chamada da África do Sul em 2018. De outra maneira, no que toca ao terrorismo, já existe um GT desde 2016 e de fato são encaminhadas práticas comuns de combate ao terror - seja em âmbito onusiano ou intra BRICS. Esse padrão também pode ser observado nas demais áreas temáticas que, embora não apresentem tanto destaque em termos de menções, tendem desde 2011 a apresentar algum tipo de coordenação política mais concreta - e, em alguns casos, se associar a uma agenda mais ampla de desenvolvimento.

(Recebido para publicação em 11 de outubro de 2019)

(Reapresentado em 15 de abril de 2020)

(Aprovado para publicação em 21 de agosto de 2020) 


\section{NOTAS}

1. Ver Abdenur e Neto (2014).

2. Ver Sun e He (2015).

3. Ver Singh (2017).

4. Ver Nyuykonge e Zondi (2017).

5. Tal índice foi calculado dividindo o número de menções ao termo "desenvolvimento" nas declarações de cúpula do BRICS, pelo número de menções a "paz" e "segurança internacional".

6. Ecaterimburgo (2009), Brasília (2010), Sanya (2011), Nova Delhi (2012), Durban (2013), Fortaleza (2014), Ufa (2015), Goa (2016), Xiamen (2017), Joanesburgo (2018) e Brasília (2019).

7. Em contraposição à cooperação em desenvolvimento, institucionalizada de forma organizacional pela criação, por exemplo, do Novo Banco de Desenvolvimento e do Arranjo Contingente de Reservas.

8. Ver Glas (2018).

9. Ver o parágrafo 13 da declaração de Ecaterimburgo (2009).

10. Ver o parágrafo 11 da declaração de Sanya (2011).

11. Ver Abdenur (2017) e Ramos et. al. (2018). 


\section{REFERÊNCIAS}

ABADI, Cameron. (2018), “The Day After the Iranian Nuclear Deal”. Foreign Policy. Disponível em: <https:/ / foreignpolicy.com/2018/12/24/the-day-after-the-iranian-nuclear-deal>.

ABDENUR, Adriana. (2017), "Can the Brics Cooperate in International Security?". International Organisations Research Journal, vol. 12, n 3, pp. 73-93.

ABDENUR, Adriana; NETO, Danilo. (2014), "Rising Powers and the Security-Development Nexus: Brazil's Engagement with Guinea-Bissau". Journal of Peacebuilding E Development, vol. $9, \mathrm{n}^{\circ} 2$, pp. 1-16.

AMMONS, Lila. (1996), “Consequences of War on African Countries' Social and Economic Development". African Studies Review, vol. 39, nº 1, pp. 67-82.

BARDIN, Laurence. (2016), Análise de Conteúdo. São Paulo, Edições 70.

BEALL, Jo; GOODFELLOW, Thomas; PUTZEL, James. (2006), "Introductory Article: On the Discourse of Terrorism, Security and Development". Journal of International Development, vol. $18, \mathrm{n}^{\mathrm{o}} 1$, pp. 51-67.

BUUR, Lars; JENSEN, Steffen; STEPPUTAT, Finn. (2007), “The Security-Development Nexus”, in L. Buur; S. Jensen e F. Stepputat (eds.), The Security-Development Nexus: Expressions of Sovereignty and Securitization in Southern Africa. Uppsala, Nordiska Afrikainstitutet.

BRICS. Join Statement of the BRIC Countries' Leaders. 2009. Disponível em: <http:/ /www. brics.utoronto.ca/docs/090616-leaders.html>. Acesso em 19 jan. 2021.

BRICS. 2nd BRIC Summit of Heads of State and Government: Joint Statement. 2010. Disponível em: <http:/ / www.brics.utoronto.ca/docs/100415-leaders.html>. Acesso em 19 jan. 2021.

BRICS. Sanya Declaration. 2011. Disponível em: <http://www.brics.utoronto.ca/docs/110414-leaders.html>. Acesso em 19 jan. 2021.

BRICS. Fourth BRICS Summit: Delhi Declaration. 2012. Disponível em: <http://www.brics. utoronto.ca/docs/120329-delhi-declaration.html>. Acesso em 19 jan. 2021.

BRICS. BRICS and Africa: Partnership for Development, Integration and Industrialisation. 2013. Disponível em: <http:/ / www.brics.utoronto.ca/docs/130327-statement.html>. Acesso em 19 jan. 2021.

BRICS. The 6th BRICS Summit: Fortaleza Declaration. 2014. Disponível em: <http:/ /www. brics.utoronto.ca/docs/140715-leaders.html>. Acesso em 19 jan. 2021.

BRICS. VII BRICS Summit: 2015 Ufa Declaration. 2015. Disponível em: <http:/ /www.brics. utoronto.ca/docs/140715-leaders.html>. Acesso em 19 jan. 2021.

BRICS. 8th BRICS Summit: Goa Declaration. 2016. Disponível em: <http:/ / www.brics.utoronto. ca/docs/161016-goa.html>. Acesso em 19 jan. 2021.

BRICS. BRICS Leaders Xiamen Declaration. 2017. Disponível em: <http:/ / www.brics.utoronto. ca/docs/170904-xiamen.html>. Acesso em 19 jan. 2021. 
BRICS. BRICS in Africa: Collaboration for Inclusive Growth and Shared Prosperity in the 4th Industrial Revolution. 2018. Disponível em: <http://www.brics.utoronto.ca/docs/180726-johannesburg.html>. Acesso em 19 jan. 2021

BRICS. Brasília Declaration. 2019. Disponível em: http:/ / www.brics.utoronto.ca/docs/191114-brasilia.html. Acesso em 19 jan. 2021

BROWN, Stephen; GRÄVINGHOLT, Jörn. (2016), “Security, Development and the Securitization of Foreign Aid", in S. Brown e J. Grävingholt (eds.), The Securitization of Foreign Aid. Nova York, Palgrave, pp. 1-17.

CHANDLER, David. (2007), "The Security-Development Nexus and the Rise of 'Anti-Foreign Policy'”. Journal of International Relations and Development, vol. 10, $\mathrm{n}^{\circ}$ 4, pp. 362-386.

COLLIER, Paul; HOEFFLER, Anke. (1998), “On Economic Causes of War". Oxford Economic Papers, vol. 50, n 4, pp. 563-573.

DUFFIELD, Mark. (2001), Global Governance and the New Wars: The Merging of Development and Security. London, Zed Books.

DUFFIELD, Mark. (2007), Development, Security and Unending War: Governing the World of Peoples. Cambridge, Polity.

GLAS, Aarie. (2018), "African Union Security Culture in Practice: African Problems and African Solutions". International Affairs, vol. 94, n 5, pp. 1121-1138.

HETTNE, Björn. (2010), "Development and Security: Origins and Future”. Security Dialogue, vol. 41, nº 1, pp. 31-52.

KONDAPALLI, Srikanth. (2016), “China and the Iran Nuclear Issue - Converting Challenges into Opportunities". Contemporary Review of the Middle East, vol. 3, n 1, pp. 63-76.

LEWIS, Jeffrey; TERTRAIS, Bruno. (2017), “The Thick Red Line: Implications of the 2013 Chemical-Weapons Crisis for Deterrence and Transatlantic Relations". Global Politics and Strategy, vol. 59, $\mathrm{n}^{\circ}$ 3, pp. 77-108.

MEDEIROS, Marcelo de Almeida; RIBEIRO, Mikelli Marzzini; LYRA, Mariana. (2017), “Em Busca de la Afirmación: Seguridad y BRICS en la Gobernanza Internacional". Foro Internacional, vol. $57, \mathrm{n}^{\circ} 3$, pp. 607-639.

NYUYKONGE, Charles; ZONDI, Siphamandla. (2017), "South African Peacebuilding Approaches: Evolution and Lessons", in C. T. Call e C. de Coning (orgs.), Rising Powers and Peacebuilding: Breaking the Mold?. Palgrave Macmillan, Cham.

OLIVEIRA, Mirian; BITENCOURT, Claudia; DOS SANTOS, Ana Clarissa; TEIXEIRA, Eduardo. (2016), "Thematic Content Analysis: Is There a Difference Between the Support Provided by the MAXQDA and NVIVO Software Packages?". Rev. Adm. UFSM, vol. 9, $\mathrm{n}^{\circ} 1$, pp. 72-82.

RAMOS, Leonardo; GARCIA, Ana Elisa; PAUTASSO, Diego; RODRIGUES, Fernanda. (2018), "Adensamento Institucional e Outreach: Um Breve Balanço do BRICS". Rev. Carta Internacional, vol. 13, n 3, pp. 5-26.

SEN, Amartya. (1993), "O Desenvolvimento Como Expansão de Capacidades". Lua Nova, $\mathrm{n}^{\circ} 28-29$, pp. 313-334. 
SINGH, Kumar. (2017). “Peacebuilding Through Development Partnership: An Indian Perspective", in Charles T. Call e Cedric de Coning (orgs.), Rising Powers and Peacebuilding: Breaking the Mold?. Palgrave Macmillan, Cham.

STERN, Maria; ÖJENDAL, Joakim. (2010), “Mappin the Security-Development Nexus: Conflict, Complexity, Cacophony, Convergence?". Security Dialogue, vol. 41, no 1, pp. 5-29.

SUN, Degang; HE, Shaoxiong. (2015), "From a By-Stander to a Constructor: China and the Middle East Security Governance". Journal of Middle Eastern and Islamic Studies, vol. 9, no 3, pp. 69-99.

VAN DER PIJL, Kees. (2017), “The BRICS - An Involuntary Contender Bloc Under Attack". Estudos Internacionais, vol. 5, $\mathrm{n}^{\circ} 1$, pp. 25-46.

VILLA, Rafael. (1994), "Segurança Internacional: Novos Atores e Ampliação da Agenda". Lua Nova, $\mathrm{n}^{\circ}$ 34, pp. 71-86. 


\section{RESUMO \\ A Agenda de Segurança Internacional no BRICS (2009-2019)}

Desde sua criação, predominaram no BRICS discussões relativas à economia política internacional, especialmente as ligadas ao desenvolvimento internacional. Entretanto, a partir das cúpulas de Sanya (2011) e Delhi (2012), questões de segurança internacional passaram a paulatinamente ocupar maior espaço dentro do grupo. Tais cúpulas são aqui entendidas como marco desse processo, e particularmente a temática da segunda, BRICS Partnership for Global Stability, Security and Prosperity, como essencial para o argumento proposto. O objetivo geral do artigo é analisar as discussões sobre segurança internacional dentro das cúpulas dos BRICS de 2009 a 2019. De modo a cumpri-lo, discute a aproximação do grupo ao nexo desenvolvimento-segurança, bem como os limites desta aproximação, e realiza uma análise de conteúdo das declarações de cúpula dos BRICS. Destacam-se na análise seis unidades temáticas e dentro de cada uma delas se sublinha a evolução das discussões e a abordagem do grupo às problemáticas.

Palavras-chave: BRICS; cooperação; segurança internacional; desenvolvimento; análise de conteúdo

\section{ABSTRACT \\ The BRICS International Security Agenda (2009-2019)}

Since its foundation in the late 2000s, BRICS was inclined to cooperate more intensely in what regards international political economy, especially topics concerned with international development. From the summits of Sanya (2011) and Delhi (2012), however, topics on international security started gradually to find its place among the group. Both summits are understood here as turning points and the later theme, BRICS Partnership for Global Stability, Security and Prosperity, as essential to the proposed argument. Having said that, the main goal of this article is to uncover the thickening of cooperation on international security among BRICS from 2009 to 2019. In order to do so, first it is debated its approach to the development-security nexus as well as its limits, and later a content analysis of the summits declarations is undertaken. Stands out from the analysis six thematic areas and inside each is highlighted the evolution of BRICS approach toward the topic.

Keywords: BRICS; cooperation; international security; development; content Analysis 


\section{RÉSUMÉ \\ L'Agenda de Sécurité Internationale dans les BRICS (2009-2019)}

Depuis sa création dans la seconde moitié des années 2000, ont prédominé dans les BRICS les discussions concernant l'économie politique internationale, notamment celles liées au développement international. Mais depuis les sommets de Sanya (2011) et de Delhi (2012), les questions de sécurité internationale ont également progressivement gagné place au sein du groupe. Les réunions sont comprises ici comme un jalon de ce processus et le thème du deuxième, le BRICS Partnership for Global Stability, Security and Prosperity, est essentiel à l'argumentation proposée. L'objectif général de l'article est d'analyser les discussions sur la sécurité internationale dans le cadre des sommets des BRICS de 2009 à 2019. Pour y parvenir, l'approche du groupe sur le lien développement-sécurité est discutée, ainsi que les limites de cette approche, et une analyse du contenu des déclarations au sommet des BRICS est effectuée. Six unités thématiques ressortent de l'analyse et au sein de chacune d'elles, l'évolution des discussions et l'approche du groupe face aux problèmes sont mises en évidence.

Mots-clés: BRICS; Coopération; Sécurité internationale; Développement; Analyse de contenu.

\section{RESUMEN}

La Agenda de Seguridad Internacional en el BRICS (2009-2019)

Desde su creación en la segunda mitad de la década del 2000, predominaron en los BRICS discusiones relativas a la economía política internacional, especialmente aquellas ligadas al desarrollo internacional. A partir de las cúpulas de Sanya (2011) y Delhi (2012), sin embargo, cuestiones de seguridad internacional pasan también a tener paulatinamente un espacio dentro del grupo. Los encuentros son entendidos aquí como marco de este proceso y la temática del segundo, BRICS Partnership for Global Stability, Security and Prosperity, como esencial para el argumento propuesto. El objetivo general del artículo es analizar las discusiones sobre Seguridad Internacional dentro de las cúpulas de los BRICS de 2009 a 2019. Para cumplirlo, se discute la aproximación del grupo al nexo desarrollo-seguridad, así como los límites de esta aproximación y es realizado un análisis de contenido de las declaraciones de la cúpula de los BRICS. Se destacan en el análisis seis unidades temáticas y dentro de cada una se subraya la evolución de las discusiones y el abordaje que dio el grupo a cada una.

Palabras clave: BRICS; Cooperación; Seguridad Internacional; Desarrollo; Análisis de Contenido 